\title{
EDUCATION
}

\section{From Technical Assistants to Critical Thinkers: From World War II to 2014}

\section{MICHELLE BUTINA, ELIZABETH KENIMER LEIBACH}

\begin{abstract}
A review of professional literature was conducted to examine the history of the education of medical laboratory practitioners. This comprehensive review included historical educational milestones from World War II to present day. During this time period the standard of two years of college required for matriculation into a medical technology program increased to four years. Critical thinking skills promoted in the educational model and applied in practice expanded from an analytic and psychomotor orientation to include those requiring extensive situational interpretation and negotiation. By the end of the twentieth century, the clinical laboratory had experienced significant scientific and technologic transformations necessitating greatly expanded roles for the medical laboratory practitioner. Though the educational requirements and education model have changed minimally since the 1970's, the knowledge and skills required for the next generation of medical laboratory practitioners continue to escalate. The second decade of the $21^{\text {st }}$ century portends a transformation in medical laboratory practitioner education commensurate with the rapid advancement of science, technology, communications, and the precepts of evidence-based practice.
\end{abstract}

ABBREVIATIONS: Affordable Care Act - ACA, Ambulatory patient groups - APG, American Society of Clinical Pathologists - ASCP, American Society for Medical Technology - ASMT, Board of Certification BOC, Board of Registry - BOR, Board of Schools BOS, Centers for Medicare and Medicaid Services CMS, Certified laboratory assistants - CLA, Clinical Laboratory Improvement Amendments - CLIA, Clinical laboratory - CL, Clinical laboratory scientist CLS, Critical thinking - CT, Doctorate in Clinical Laboratory Science - DCLS, Diagnosis Related Groups - DRGs, Electronic health records - EHR, Evidencebased practice - EBP, Health informatics - HI, Health Information Technology for Economic and Clinical
Health - HITECH, Health Insurance Portability and Accountability Act - HIPAA, Healthcare Financing Administration - HCFA, Laboratory aide - LA, Medical technologist - MT, Medical laboratory scientist - MLS, Medical laboratory technician - MLT, National Accrediting Agency for Clinical Laboratory Sciences NAACLS, National Certification Agency - NCA, Problem-based learning - PBL, Quality control - QC, Research and development - R\&D, Specialist in Blood Bank - SBB, Specialist in Chemistry - SC, Specialist in Microbiology - SM, World War II - WWII

INDEX TERMS: Board of Registry, critical thinking, curriculum, education, history, evidence-based practice, health education, allied health

Clin Lab Sci 2014;27(4):209

Michelle Butina, PhD, MLS(ASCP) ${ }^{C M}$, Medical Laboratory Science University of Kentucky, College of Health Sciences, Lexington, $K Y$

Elizabeth Leibach, EdD, MLS ${ }^{C M}, S B B^{C M}$, Principal Officer, HMES, Augusta, GA

Address for Correspondence: Michelle Butina, PbD, MLS(ASCP) $)^{C M}$, Assistant Professor and Program Director, Medical Laboratory Science University of Kentucky, College of Health Sciences, 900 South Limestone Street, CTW Bldg. Rm. 126E, Lexington, KY 405360200, - 859) 218-0852 Michelle.Butina@uky.edu

"Education has to be re-energized periodically in order to keep the speed of the mind and technical know-how up to the speed and needs of the rapidly increasing demands of the times...it is apparent that the processes of education that worked 45 years ago, or last year for that matter, are likely to become more or less ineffective, as happened to the horse and buggy"

-Lall G Montgomery, MD (Chair of the Board of Registry from 1940-1964, a Founding Fellow of College of American Pathologists, and past President of the American Society of Clinical Pathologists) address given to medical technologists at University of Vermont, 1966 as quoted in Fruchtl, 1968 ${ }^{1}$ 


\section{INTRODUCTION}

The article that follows is the second half of a historical research project focused on the educational milestones experienced by an evolving, adapting medical laboratory science profession. The first article highlighted milestones from the 1890's until the advent of World War II (WWII) while this sequel focuses on milestones from WWII to the present. Within the educational historical milestones that follow, the growth of critical thinking (CT) in medical laboratory science is highlighted. Major practitioner education milestones during this time period are presented in Table 1 while major education program requirements/standards are presented in Table 2. This article concludes with considerations for the future educational preparedness of medical laboratory practitioners at all practice levels.

Table 1. Major educational milestones from 1940 to 2014

1944 Practical section of Board of Registry examination is eliminated. ${ }^{2}$

1947 Laboratory Aide category of certification is established.2

1949 Board of Registry examination transitions to a multiple choice question format. ${ }^{2}$

1949 Board of Schools is established to accredit acceptable educational programs. ${ }^{3-4}$

1952 First special certificates in Bacteriology issued. ${ }^{2}$

1962 Three years (90 semester hours) is required prior to entering an approved program $/$ school. $^{10}$

1966 Allied Health Professions Personnel Training Act is passed. Allows for development of numerous medical laboratory technology programs. ${ }^{26,27}$

1969 Board of Registry begins offering certifying examination for medical laboratory technician practice level. ${ }^{20,24}$

1972 Board of Registry established baccalaureate degree as minimum requirement for MT certification. ${ }^{4}$

1973 Board of Schools is dissolved and National Accrediting Agency for Clinical Laboratory Sciences is established and begins operation in $1974 .^{21,35}$

1977 National Certification Agency for medical laboratory personnel is established. ${ }^{21,35}$

2009 National Certification Agency and the Board of Registry merge and Board of Certification is established. ${ }^{60}$

2014 Doctorate in Clinical Laboratory Science is established. ${ }^{59}$

\section{0-1960}

\section{Praxis Environment}

Due to restricted travel during World War II (WWII), the Board of Registry (BOR) discontinued the practical component of the certification exam in 1944, retaining only the essay written component. (Practical examinations were set up in central locations requiring applicants to travel.) $)^{2}$ In 1948, the BOR changed the essay written exam to an exam composed of multiplechoice and true-false questions that could be easily scored by machines. In 1949, the BOR changed the format to a 200 multiple choice question exam as they found these questions to be more reliable than truefalse. $^{2}$ Also in this same year, the BOR ceased one of its original functions of registering programs/schools and the Board of Schools (BOS) was established to award and maintain accreditation of acceptable educational programs. ${ }^{3-4}$

Table 2. Major educational requirements/standards from 1920 to 2014.

1928 ASCP committee became the "Board of Registry of Laboratory Technicians" (BOR). ${ }^{73}$

1933 One year of college is required prior to entering an approved program/school. ${ }^{2}$

1938 Two years of college is required prior to entering an approved program $/$ school. $^{73}$

1962 Three years (90 semester hours) is required prior to entering an approved program/school. ${ }^{10}$

1972 BOR established baccalaureate degree as minimum requirement for $\mathrm{MT}$ certification. ${ }^{4}$

After WWII, the demand for laboratory personnel intensified with an increase in military and civilian hospital laboratories, development of public health laboratories, new test procedures and methods, and the acceptance of routine laboratory tests in overall health assessment. ${ }^{5}$ This amplification, created a need for a laboratory aide, similar to the nursing aide that was developed during the war, to assist medical technologists (MT). ${ }^{2,6}$ In 1947, the BOR established certification for the laboratory aide (LA) category in which applicants were required to have a high school diploma. Initially, the BOR had very few applicants for examination and it was not until the mid-1950s that formal training for this level was developed. , $^{27}$

In 1944, Dr. Kano Ikeda (Secretary and later Chair of the Committee on the Registration of Technicians and founding member of Board of Registry) advocated for specialized expert service in the different departments of the laboratory even though he recognized that only larger hospitals organized laboratories according to subdisciplines. ${ }^{8}$ The sub-disciplines he mentioned included bacteriology, biochemistry, hematology and serology. ${ }^{8}$ He suggested that medical technologists should specialize in one of these sub-discipline so that individual pathologists would not be required to be 


\section{EDUCATION}

accomplished in all areas: bacteriology, biochemistry, hematology and serology. However the role of interpretation would remain the purview of the pathologist. Dr. Ikeda believed this was the next logical step for the new medical technology profession and proposed that those seeking a specialist certification in medical technology should have postgraduate training in the sub-discipline. ${ }^{8}$ In 1952, the first specialist in microbiology (SM) certificate was issued and, two years later, the first specialist in chemistry (SC) and blood bank (SBB) were issued to those individuals who had obtained master's or doctoral degrees in the specialties. ${ }^{2}$ Then in 1965, the BOR extended specialties to those medical technologists who had obtained a bachelor's degree and five years' experience in a subdiscipline. ${ }^{2}$

\section{Education Program Organization}

During the 1950's BOS-approved programs increased dramatically. In 1950, there were 436 approved programs and by 1958 there were over 650.5 This increase resulted from recruitment efforts to supply the high demand for medical technologists that began after WWII. In order to meet this demand the American Society of Clinical Pathologists (ASCP), the American Society for Medical Technology (ASMT, now the American Society for Clinical Laboratory Science), and the College of American Pathologists formed the National Committee for Careers in Medical Technology. This committee developed recruitment materials (literature and movies) and the BOR office served as the primary distributor of these materials. The successful outcomes of this recruitment committee were demonstrated by the growth of approved programs and higher enrollment numbers. The benefits of this collaborative recruitment effort were numerous, with only one major shortcoming, the lack of educators in academia and as coordinators of hospital-based clinical experiences. ${ }^{2,5}$

Educational programs were apprenticeship type models that emphasized repetition of the manual laboratory techniques advanced during the period. However because the majority of stakeholders (educators, medical technologists, and pathologists) believed that medical technology education should be based on pedagogical principles rather than psychomotor repetition, the popular apprenticeship model began to receive heavy criticism. ${ }^{7,9}$ Arens (1955) does point out that education, in general, shifted during this time as women were now being accepted into fields that were traditionally maledominated. ${ }^{7}$ This shift in workforce toward fields traditionally male-dominated contributed to the laboratory personnel shortage.

As the number of laboratory procedures available and frequency of ordering these tests increased, pathologists delegated more analytic work to medical technologists. ${ }^{7}$ Testing evolved to more complex and specialized procedures. Independent technical judgment, including analytic problem solving, was now shifted to the medical technologist. Further, medical technologists began to manage non-analytic workflow in the departments. Therefore CT capabilities and applications for clinical reasoning, negotiation, time management, and judgment grew. More cognitive and psychomotor aspects of this progression in CT were evidenced by the recognition of another sub-discipline, immunology, and development of additional specialty certifications, not only in immunology, but also in clinical laboratory management.

\section{0-1970}

\section{Practice Evolution}

In 1958, the BOR proposed to increase the prerequisite of two years' college work to three years $(90$ semester hours) prior to entering an approved program. The three year prerequisite for entrance into an approved medical technology program, which included 16 semester hours in biology, 16 in chemistry, plus 3 hours in mathematics, became effective January $1,1962 .{ }^{10}$ It was strongly recommended that students complete one semester of bacteriology and physics. Frequently students were able to complete a degree in medical technology after completion of the approved program. The certificate earned was considered equivalent to credit hours, and as such, a degree could be granted. (The practice of conferring a Bachelor of Science in Medical Technology after 3 years of college courses and one year of training in an approved programs began in the 1930 's. $)^{2,10}$

Science and industry exploded during the postwar years due to the growth in research and development (R\&D). The $R \& D$ industry grew from a small number of laboratories to a $\$ 20$ billion a year industry by $1965 .{ }^{11}$ Hospital laboratories benefited from this scientific revolution with the introduction of computers and automated analyzers. In the late 1950's, the forerunners 
of today's automated analyzers appeared, the Technicon AutoAnalyzer 1 (Figure 1), first clinical chemistry analyzer, and the Model A Coulter Counter $\rightarrow$ (Figure 2), first hematology analyzer. ${ }^{12-13}$ The Technicon AutoAnalyzer started a "technological revolution in clinical chemistry" that eventually expanded to all subdisciplines in laboratory medicine. ${ }^{14}$

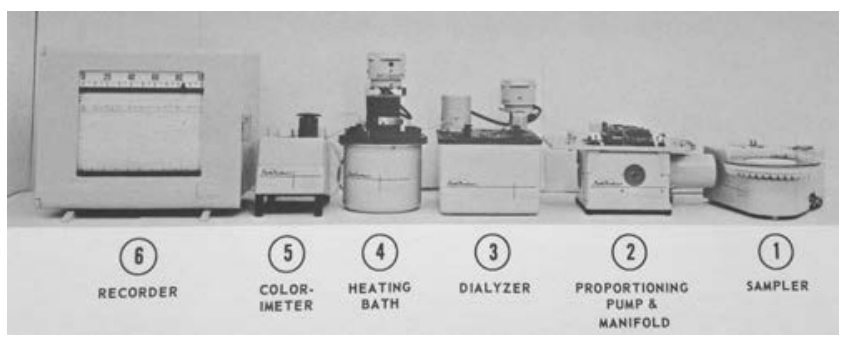

Figure 1. Technicon AutoAnalyzer 1. Published with the express permission of SEAL Analytical Inc., Mequon, Wisconsin, USA.

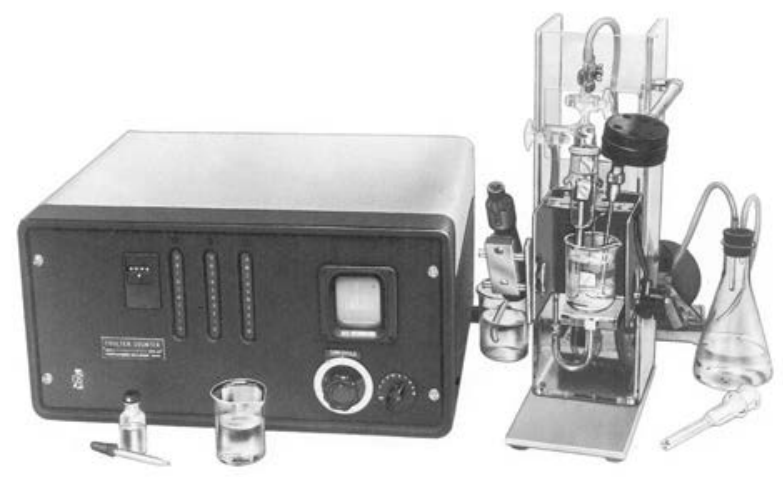

Figure 2. Model A Coulter Counter

With technological advancement came questions of quality. Intending to improve, document, and monitor testing reliability, large chemistry departments began development of statistical quality control (QC) programs with the introduction of quality control charts in $1950 .{ }^{15-17}$ QC charts "provided a constant check on the reliability of the numerous determinations run each day" and when a method was out of control it was up to the medical laboratory practitioner to "study the cause and prevention of the error." 15 As automation moved from chemistry into other sub-disciplines, such as hematology, QC programs followed to ensure that these "complex" instruments were performed with accuracy and precision. ${ }^{18-19}$

The automation boom of the 1960s changed laboratory testing and expanded the role of medical technologists.
As Kotlarz explains, "the advent of laboratory automation diminished the need for technical skills and called for new types of skills and knowledge." ${ }^{20}$ The new knowledge and skills would include electronic communications and validation, instrumentation interoperability and maintenance, and principles of quality assurance. Critical thinking supporting problem solving incorporated more knowledge about complex physiological pathways (cognitive and situated domains) and diverse technical methods (cognitive and psychomotor domains).

\section{Education Program Evolution}

During this period, the majority of programs were organized as $3+1$ programs in which the clinical or practical component, in a hospital laboratory, occurred during the senior or fourth year and was administered separately from the academic component. Concerns arose, however, because of the lack of didactic, formal academic curriculum during the clinical experience. A movement began to ensure the clinical component was at a level comparable to the academic component; provide a balance between liberal arts, sciences, medical laboratory sciences and clinical experiences; transition away from vocational-type training of repetitious technical procedures; and promote critical thinking and problem solving skills. ${ }^{20}$

The creation of allied health schools or colleges facilitated the integration of academic and clinical components, promoting extension of academic components into the clinical experience, thus creating clinical practicums modeled on medical education. This shift also resulted in the formalization of laboratorybased courses in the academic component while enhancing the clinical components. The addition of a student laboratory component within the college/university setting allowed for more thorough and standardized basic laboratory skills presentation and, therefore, better learning transfer to the practice environment. Furthermore, it allowed for the traditional 12-month clinical experience to be reduced commensurately. ${ }^{20-21}$

These changes resulted in a new program model, the $2+2$, in which the curriculum is divided evenly into preprofessional and professional phases that include student laboratories and a clinical component at an affiliated hospital, respectively. The advent of this more 


\section{EDUCATION}

experiential environment paralleled the development of constructivist theory positing the importance of reflection on and incorporation of real life experiences for more effective learning transfer. ${ }^{22}$ The $2+2$ model allowed for a more rapid acquisition of new knowledge and diverse skills needed for the increasingly complex laboratory milieu. ${ }^{20-21}$

In 1964, the BOR discontinued the laboratory aide category and replaced it with the new certified laboratory assistants (CLAs) category, the second generalist level certification. ${ }^{23}$ In 1969, the BOR offered a certifying examination for the medical laboratory technician (MLT) practice level. $^{20,24}$ Need for this practice level arose in 1965 with the advent of the Medicare-Medicaid "Great Society" legislation which created significant workforce needs in healthcare. To meet workforce demands the federal government offered stimulus funding for development of allied health programs. $^{25}$ In 1966, the Allied Health Professions Personnel Training Act was passed to "increase the opportunities for training of medical technologists and personnel in other allied health professions and to improve the educational quality of the schools training such personnel" by providing grants for construction of facilities, improvement of facilities, curriculum development, and training of teachers in junior and community colleges. ${ }^{26}$

With great zeal junior and community colleges quickly developed numerous allied health programs to meet the healthcare workforce need. ${ }^{27}$ The expansion of medical laboratory technology programs occurred rapidly; however, standards for curriculum, job description, certifying examination, and accrediting programs developed later. ${ }^{24}$ It was not until the 1970's that standards were clearly defined and developed to ensure the quality of these laboratory practitioners.

As the $2+2$ education model gained prominence, development of CT skills in cognitive and behavioral (psychomotor) domains was focused in the didactic (academic and laboratory-based course) curriculum phase. Education related to the more contextual CT skills (affective and situated domains) developed within the purview of the practicum curriculum phase. Problem solving (technical, instrumental or physiological/disease management) was a significant activity of both medical technologists and medical laboratory technicians requiring different complexity levels of CT skills. ${ }^{28}$ Students developed these skills by observation (modeling) of medical technologists and medical laboratory technicians, in discussions with them (mentor to student), or simply "trial by fire" (alternatives identification and problem-solving). ${ }^{29}$

\section{0-2000}

\section{Healthcare Evolution}

Computers were introduced in the clinical laboratory by the late 1960's. During the next decade computers revolutionized the clinical lab along with consistent advances in instrumentation and automation. Computers networked instruments and processed data; however laboratory information systems were not available until the 1980 's. ${ }^{14}$ In the 1990 's robotics were introduced for specimen processing and automated assays in clinical chemistry and hematology. ${ }^{30}$ Immunoassay diagnostics expanded clinical chemistry testing, biosensor advances promoted development of point of care instruments, and DNA technology moved from the research laboratory to clinical applications in the laboratory. ${ }^{31}$

During these decades government involvement in the clinical laboratory increased significantly, as well. Prior to this time clinical laboratories, reimbursed under a fee-for-service schedule and direct capital expenditure pass-through by Medicare (through the U.S. Healthcare Financing Administration, HCFA, now Centers for Medicare and Medicaid Services, CMS), expanded in human resources and technology. In 1983, HCFA established a prospective payment system for inpatient hospital services, diagnosis related groups (DRGs), requiring new cost accounting in which the lab transitioned from a profit center to a cost center. ${ }^{14}$ In 1986, HCFA initiated a prospective payment outpatient fee schedule, ambulatory patient groups (APG), as well. Shortly thereafter other insurance carriers adopted similar payment mechanisms thereby significantly decreasing and limiting laboratory operating margins. ${ }^{32}$

In 1988, clinical laboratory regulation increased again with consumer protection legislative amendments to the Clinical Laboratory Improvement Act (CLIA) of 1967. The 1967 CLIA law had introduced minimal regulations for laboratories that processed more than 100 specimens per year in interstate commerce. The CLIA Amendments of 1988 introduced additional 


\section{EDUCATION}

regulation, for all clinical laboratories, that defined quality and staffing requirements by complexity of testing performed. ${ }^{33}$ The 1980 's was a turbulent time for laboratory administrators as clinical laboratories faced decreased budgets, increased costs, and reduced reimbursement.

Legislation was introduced in the "Stark Provision" of the Omnibus Budget Reconciliation Act of 1989 which barred physician self-referrals for clinical laboratory services under the Medicare program. ${ }^{34}$ With full implementation of these rules in 1992, further restrictions were placed on business models available to laboratory owners and investors, particularly in inpatient services delivery. Coupled with DRG implementation and higher quality and automation costs, this restriction on reimbursement completed the shift from revenue to cost center in inpatient services accounting. Many clinical laboratories had no choice but to consider mergers, partnerships, and downsizing in order to provide cost-effective testing. ${ }^{32}$

Rapid advancement of technology, automation, and computerization within an expanded regulatory environment affected medical laboratory educational programs and practitioners, also. In response to ASMT agitation for more voice in determination of practice entry requirements, the BOR established a minimum requirement of a baccalaureate degree for MT certification in 1972. ${ }^{4,35}$ After a series of antitrust legal challenges resulting in a U.S. Office of Education opinion in 1972 that the BOS should be autonomous, the ASCP dissolved the BOS in 1973 and a new independent agency was formed to develop and approve medical technology programs. The National Accrediting Agency for Clinical Laboratory Sciences (NAACLS) was created and began operation in $1974 . .^{21,35}$

\section{Profession Evolution}

Another antitrust challenge came in 1976 when the Federal Trade Commission initiated a general inquiry into barriers to competition in health services delivery. ASMT claimed that credentialing by ASCP placed certified MTs at risk of anti-competitive "collusion and control of a segment of the healthcare industry." ${ }^{35}$ Having been unsuccessful in negotiating an increased voice for MT within ASCP, the ASMT acted on this opportunity to establish physician-independent certification. This long-envisioned milestone was reached in 1977 with the establishment of the National Certification Agency (NCA), an independent credentialing body for certification of medical laboratory personnel governed by medical technologists certified as clinical laboratory scientists, CLS(NCA). ${ }^{21,35}$ At this historical juncture, there were two credentialing bodies, the BOR, a standing committee of ASCP and the NCA an autonomous, non-physician controlled certifying agency.

By this time, MTs and CLSs were the predominant professionals in laboratory administrative roles such as section (sub-discipline) supervisors, chief technologists, laboratory directors, hospital administrators, and directors of programs of medical technology. ${ }^{36}$ MTs/CLSs were routinely responsible for supervisory duties such as budget management, cost analysis, developing policies, hiring and discharge, instrument evaluation, performance evaluations, and scheduling. ${ }^{37,38}$ As more MTs/CLSs assumed these roles the lack of business education became an issue. Medical technology programs began adding courses in management and supervision, more medical technologist sought master degrees, and laboratory administration sessions were added to ASMT meetings. ${ }^{39}$ Professional, graduate, and continuing education curricula expanded to include business operations components related to organizational development and change, human resources and staffing strategies, cost characterization and allocation, and revenue and reimbursement.

By the 1980's career opportunities had further expanded for MTs/CLSs beyond traditional technical and administrative positions within hospitals. In 1982, The U.S. National Labor Relations Board granted professional status to medical technologists as distinct practitioners apart from medical laboratory technicians who were recognized as non-professionals. ${ }^{40}$ The professional scope of practice increasingly included nontechnical positions within healthcare, e.g., consultants, education coordinators, infection control officers, quality assurance directors, laboratory administrators, safety director, health informatics, as well as outside of healthcare, e.g., academia, government agencies, industry, insurance, sales, information technology. ${ }^{41}$ Medical laboratory technicians now performed many routine laboratory tasks while MTs/CLSs designed 


\section{EDUCATION}

quality improvement programs, managed operations and human resources, and developed and implemented computer applications and systems.

\section{Education Program Reorganization}

Despite the dramatic increase in scope of practice, the number of educational programs steadily declined especially in hospital-based programs during the decade 1980-1990. Drivers for these closures included program expense, lack of personnel in clinical sites, low enrollment and student training time, and affiliations with university-based programs utilizing the $2+2$ model. ${ }^{21,42}$ Programs creatively addressed recruitment issues, became more cost effective, and maintained and even expanded clinical sites. Outcomes included reduced practicum times balanced with increased time for student laboratories, increased articulation with medical laboratory technology programs, introduction of distance learning programs, and integration of computer programs/tutorials and the Internet in teaching. ${ }^{43-45}$

The scientific and technological advances of the last few decades led to transformations in education and different levels of practice. As intra-laboratory and external electronic systems replaced traditional paperbased record systems and manual assays, education and practice were transformed. As Kotlarz described, “... the nature of clinical laboratory practice changed, it became increasingly important for MTs to apply theoretical knowledge to the analysis and solution of problems. They were expected to develop problem-solving skills to identify and correct errors in laboratory analysis, to troubleshoot laboratory instrument malfunctions, and to apply principles of education, management, and supervision to the daily operation of the clinical laboratory." 36

Educational programs began emphasizing new skills such as communication, computer, data management, laboratory management, professionalism, and research. ${ }^{21,39,46}$ Educators had to increase the promotion of CT skills in their curricula to ensure students could adapt to change, analyze problems, manage personnel, communication effectively, and grow as professionals. ${ }^{46}$

\section{0-2014}

\section{Healthcare Expansion}

Regulation and technological advances continue to drive healthcare expansion into the first two decades of the $21^{\text {st }}$ century. The opening salvo of the millennial regulatory revolution occurred with passage of the Health Insurance Portability and Accountability Act (HIPAA) in 1996. A shift in legal ownership of health records from provider to patient/consumer began amidst the formulation of rules defining personal health information, privacy, and informed consent. ${ }^{47}$ Additional regulations protecting individual ownership of health information and exchange (sharing) of health information came in 2009 with the passage of Protection of Human Subjects rules in the U.S. Code of Federal Regulations ${ }^{48}$ and the Health Information Technology for Economic and Clinical Health (HITECH) Act, ${ }^{49}$ respectively. The HITECH Act, in addition, mandated the development and adoption of electronic health records (EHR) as a requirement for Medicare and Medicaid services reimbursement through CMS. In 2010, Congress passed the Patient Protection and Affordable Care Act, better known as the Affordable Care Act (ACA), with the goal of insuring the healthcare needs of all Americans. ${ }^{50}$ Then in 2014, rules appeared in the U.S. Federal Register amending CLIA and HIPAA rules to give patient/consumers direct access to their clinical laboratory test reports. ${ }^{51}$ These far-reaching regulatory changes have set the stage for radical expansion in scope of practice of MTs/CLSs to include interpretation and evaluation of personal health information for clinical decision support and consultation and evidence-based practice (EBP) using EHR-based informatics and analytics.

Research in the clinical laboratory during the first two decades of the twenty first century has been varied. Prominently reported are the advances in molecular biology resulting in the rapid development of applied clinical molecular testing and the inclusion of either a dedicated molecular diagnostics course or components incorporated throughout the professional curriculum as required by NAACLS. ${ }^{52,53}$ During the past decade, these molecular assays have permeated the clinical laboratory and are now routine in most microbiology labs. ${ }^{54}$ Technological advances in molecular techniques and clinical applications are also increasing demand for computational resources and skills, both material and human, respectively.

Research in health services delivery also figures prominently into clinical laboratory science with 
advances in quality theory applied through methods of EBP. ${ }^{55}$ EBP methods have provided the mechanism for evaluation of impact of clinical laboratory (CL) information on health outcomes. The ability to mine EHR information for these linkages between CL information and health outcomes has radically expanded our definition of patient safety to include a focus on the value we add to patient/consumers' care paths. Assessing the impact of laboratory services on patient safety and health outcomes is a cornerstone, not only of CL quality improvement, but also of institutional total quality management given the pivotal role of CL information in EBP of all healthcare practitioners. The need to mine EHR information for clinical decision support maximizing $C L$ value for patient/consumers has also created a need for CL health informatics (HI) development and education. Analysis of patient/consumers' progress along their care path using $\mathrm{HI}$ analytics will be a central function of the doctorate in clinical laboratory science (DCLS)..$^{56}$

\section{Profession Reorganization Forces}

In 2005, the current ASCLS President, Susan Morris, formed the Professional Doctorate Task Force to develop and promote the profession's advanced practitioner, the DCLS. ${ }^{57-58}$ As of 2014, DCLS programs are approved and enrolling students to address the skills required for the millennial healthcare expansion. ${ }^{59}$ This clinically-oriented doctorate consults with healthcare providers on selection and interpretation of laboratory tests, providing clinical decision support, while also consulting with consumers to prepare them to share in healthcare decision-making.

During the same period of doctoral advanced practice development, certification options for the entry level practitioner, MT/CLS, decreased. In 2009, the NCA and $\mathrm{BOR}$ reorganized to form a single certification body, the Board of Certification (BOC) certifying both medical laboratory scientists (MLS, formerly medical technologists and clinical laboratory scientists) and medical laboratory technicians. ${ }^{60} \mathrm{~A}$ step back from the professional autonomy offered by the NCA, the BOC is organized under and administered by the ASCP; its board of governors is comprised of physicians as well as non-physician MLS.

Though indicating a degree of loss of professionalism for MLS, the unification of certification boards served to define the MLS scope of practice for the entire industry and clarify the need for and competencies of the DCLS advanced practitioners. To adequately attest and standardize scope of knowledge and practice of the DCLS advanced practitioner, a separate and independent certification process will be developed which reflects the complex critical thinking skills and practice competencies required in the healthcare expansion. Even though MLS certification has led to state licensure in only 12 states, ${ }^{61}$ DCLS certification is expected to be the primary qualification for licensure in all U.S. states and other countries. ${ }^{59}$

\section{Education Program Reorganization Forces}

Trending in all areas of allied health is utilization of educational instructional technology. Faculty consistently use learning management systems, and have a plethora of technological resources to assist them in teaching and interacting with students such as classroom response systems, e-books, pod-casts, social networks, etc. Many programs offer some form of online instruction, either blended (hybrid) courses, single online courses, or entire online programs. ${ }^{62-64}$ Additionally, some programs have developed virtual, simulated laboratories and/or transitioned to virtual, digital microscopy. ${ }^{65-67}$

Though the development of CT skills has been incorporated into the curriculum of medical laboratory practitioners in both the academic and clinical components for decades, approaches and methods for increasing CT have included the addition of problembased learning (PBL) exercises (often case studies) and clinical simulations have emerged within the last decade. These approaches foster development of CT skills by systematically solving problems and integrate knowledge from across all laboratory disciplines. ${ }^{68}$ Another educational approach promoting CT is the inclusion of research design and practice into the curriculum. ${ }^{69}$

\section{CONCLUSION}

The education model today includes more college/university based programs than hospital-based $2+2$ programs. Educators have creatively expanded this traditional model to include blended courses, entry-level master's, flipped classrooms, virtual laboratories, abbreviated practicums, reduced program lengths, and/or distance/online programs. ${ }^{62-67,70-71}$ Yet as the roles 
of medical laboratory practitioners expand, how can programs continue to incorporate the newer knowledge (healthcare reform, reimbursement, genetics, and molecular based testing) and skills (e.g., more critical thinking, advanced molecular diagnostics, interprofessionalism, advocating, consulting, and research) required to support the profession in the millennial healthcare expansion?

This article has described the evolution of the educational requirements of medical laboratory practitioners since the 1940 's. The expansion of knowledge and skills required of medical laboratory practitioners has been significant. Yet, areas of ambiguity exist among professional (MLS) and nonprofessional (MLT) curricula with an apparent lack of recognition of differences in types and complexity of CT skills characteristic of each practice level. Likewise, additional CT skills required for master's level practice, e.g., business operations and finance, and technical specialties, e.g., SBB, have not been thoroughly described and formally documented and evaluated in curriculum. DCLS program development has begun identification of CT skills required for workforce integration at this practice level. ${ }^{57,58}$ Requirements of the rapid healthcare expansion viewed through this lens of history suggest a hierarchical realignment of competencies, among practice levels based on CT skill complexity required in practice, increasing in scope and complexity from MLT to DCLS.

Many allied health professions have increased entrylevel educational requirements, necessitated by expansion of knowledge and scope of practice. The medical laboratory profession, arguably much broader in scope than most, has not recognized our practice levels as comprised of shared competencies to be taught in sequence building in CT complexity from MLT to DCLS. As a result, we are not the first to suggest that our educational model suffers from "paralysis" thus we realize changes to the model will not happen immediately. ${ }^{72}$ However we hope that correlating our profession's developmental milestones to the evidence of history, fellow educators and practitioners will be inspired to review our current educational models and standards through a CT rubric.

\section{REFERENCES}

1. Fruchtl MM. New curriculum design in medical technology education. Am J Med Tech 1968;34(10):601-12.

2. Montgomery LG. A short history of the registry of medical technologists of the American Society of Clinical Pathologists. Am J Clin Path 1970;53:433-46.

3. Kotlarz VR. Tracing our roots: Progress in advancing the profession (1945-62). Clin Lab Sci 1999;12(2):91-7.

4. Rodriquez FH, Ball JR. The American Society for Clinical Pathology: The pathology society of "firsts". Lab Med 2007;38(10):595-601.

5. Kotlarz VR. Tracing our roots: The broadening horizons of clinical laboratory practice (1945-62). Clin Lab Sci 1998;11(6):339-45.

6. Ikeda K. The present trends in medical technology. Am J Med Tech 1951;17(2):81-8.

7. Arens MA. Medical technology-education problems. Am J Med Tech 1955;21:65-74.

8. Ikeda K. Specialization in medical technology. Am J Med Tech 1944;10:159-64.

9. Arnold JG. Current educational standards in medical technology. Am J Med Tech 1960;26:101-10.

10. Anonymous. College education for students entering approved schools of medical technology. Tech Bull 1966;36:51-2.

11. Kimball C. Changing demands of science and technology. Am J Med Tech 1965;31:207-12.

12. Graham MD. The Coulter principle: Foundation of an industry. J Assoc Lab Autom 2003;8(6):72-81.

13. Skeggs LT. An automatic method for colorimetric analysis. Am J Clin Path 1957;28:311-22.

14. Benson ES. The past as prologue: A look at the last 20 years. Med Lab Obs 1989;21(7)27-31.

15. Levey S, Jennings ER. The use of control charts in the clinical laboratory. Am J Clin Path 1950;20:1059-66.

16. Hoffmann RG, Waid ME, Henry JB. Clinical specimens and reference samples for the quality control of laboratory accuracy. Am J Med Tech 1961;27:309-17.

17. MacDonald H, Foote EK, Baker ER. The establishment of a clinical chemistry quality control program. Am J Med Tech 1961;27:129-36.

18. Richterich R. Quality control in the clinical laboratory. Am J Med Tech 1965;31:149-50.

19. Thiers RE. Quality control has its brightest day in clinical chemistry. Am J Med Tech 1965;31:146-8.

20. Kotlarz VR. Tracing our roots: A new era in clinical laboratory science education. Clin Lab Sci 1999;12(4):213-19.

21. McKenzie SB. History of clinical laboratory science education. Clin Lab Sci 1992;5(4):221-6.

22. Schon, D.A. Educating the reflective practitioner: Toward a new design for teaching and learning in the professions. San Francisco: Jossey-Bass, Inc., 1996

23. Anonymous. ASCP Board of Registry celebrates 75 years. Lab Med 2003:34(12):829-31.

24. McDonald J, Hedrick W. A survey of medical laboratory technician (MLT) programs in the United States. Am J Med Tech 1974;40(6):277-84.

25. Holley J. State of the art in medical laboratory technician programs. Am J Med Tech 1975;41(2);86-9.

26. United States. Allied health professions personnel training act of 1966: Hearings, Eighty-ninth Congress, second session, March 29, 30, and 31, 1966. Washington: U.S. Govt., 1966

27. Connelly T. Allied health personnel education and the junior 
college concept. Am J Med Tech 1972;38(4):115-21.

28. ASMT position paper. Differentiation among MT, MLT and CLA expected capabilities at career entry. Am J Med Tech 1973;39(9):362-4.

29. Southern D. Laboratory education in the 1950s and 1960: A trip down memory lane. Clin Lab Sci 1999;12(1):30-4.

30. Lifshitz MS, DeCresce RP. Automation: Trends in instrumentation, robotics, computers. Med Lab Obs 1989;21(7):73-7.

31. DeCresce RP, Lifshitz MS. The impact of new technology. Med Lab Obs 1989;21(7):41-6.

32. Hirsch PT. New lab consolidations: competing on a cost basis. Med Lab Obs 1989;21(7):69-71.

33. Sisk FA. Trends in regulation and reimbursement. Med Lab Obs 1989;21(7):49-55.

34. Stark Law.org. Stark Law Guidelines 2013 [cited 2014 Aug 31]42 C.F.R. $\$ 411.350$ through $\$ 411.389$. Available from http://starklaw.org/stark_guidelines.htm.

35. Kotlarz VR. Tracing our roots: Years of turmoil (1962-1977). Clin Lab Sci 1999;12(6):336-41.

36. Kotlarz VR. Tracing our roots: The rocky road toward recognition of clinical laboratory science's professional status (1962-1977). Clin Lab Sci 2000;13(3):166-71.

37. McClure JL, Bayliss FT. Medical technologist supervisors: Are they prepared to manage? Am J Med Tech 1978;44(2):97-111.

38. McBride K. Task analysis of medical technology administration and supervision. Am J Med Tech 1978;44(7):688-95.

39. Vittetoe MC. Development of administrative roles for medical technologists. Am J Med Tech 1982;48(9):727-31.

40. U.S. National Labor Relations Board. Medical Technologists are Professional Employees. Case 33-RC-2460. 261 NLRB No. 155. 1982. [cited 2014 Sep 27] Available from http://www. nlrb.gov/case/33-RC-002460

41. Kotlarz VR. Tracing our roots: New opportunities and new challenges in clinical laboratory science (1977-1992). Clin Lab Sci 2001;14(1):13-17.

42. Castleberry BM. Who will staff the laboratory of the '90s? Med Lab Obs 1989;21(7):59-66.

43. Bruce W, Bruce JM, Paur RA. A new paradigm for clinical laboratory science education: A case study for survival and growth. Clin Lab Sci 1997;10(1):38-42.

44. Kiser KM. Integrating the internet into lesson plans. Clin Lab Sci 1999;12(4):196-8.

45. McCoy C. CLS education programs: Status and future directions. Clin Lab Sci 1997;10(1):32-7.

46. Beck SJ. Assessing the educational preparation of clinical laboratory scientists. Clin Lab Sci 1994;7(5):293-9.

47. Health Insurance Portability and Accountability Act (HIPAA) of 1996 [cited 2014 Aug 31] Pub.L. 104-191, 110 Stat. 1936. Available from http://www.gpo.gov/fdsys/pkg/PLAW104pub 1191/html/PLAW-104publ191.htm.

48. Protection of Human Subjects, "Common Rule"; 2009 [cited 2014 Aug 31] 45 CFR part 46. Available from http:// www.hhs.gov/ohrp/humansubjects/guidance/ $45 \mathrm{cfr} 46 . \mathrm{html}$.

49. Health Information Technology for Economic and Clinical Health (HITECH) Act enacted under Title XIII of the American Recovery and Reinvestment Act of 2009 [cited 2014 Aug 31] Pub.L. 111-5. http://www.gpo.gov/fdsys/pkg/BILLS$111 \mathrm{hr} 1 \mathrm{enr} / \mathrm{pdf} / \mathrm{BILLS}-111 \mathrm{hr} 1 \mathrm{enr}$.pdf.

50. Patient Protection and Affordable Care Act. "Public Law 111-
148". 111th United States Congress. Washington, D.C.: United States Government Printing Office. March 23, 2010 [cited 2014 Sep 27] Available from http://www.hhs.gov/ healthcare/rights/law/

51. CLIA Program and HIPAA Privacy Rule; Patients' Access to Test Reports (CMS-2319-F), Federal Register February 6, 2014 [cited 2014 Aug 31] 75(25): 7290-7316. Applicable Code: 42 C.F.R. Sect. 493, 45 C.F.R. Sect. 164. Available from https://www.federalregister.gov/articles/2014/02/06/2014 -02280/clia-program-and-hipaa-privacy-rule-patients-access-totest-reports.

52. Kraj B, Pretlow L, Russell B. Student molecular laboratory performance outcomes in a baccalaureate CLS program. Clin Lab Sci 2011;24(4):31-36.

53. Rohde RE, Falleur DM, Kostroun P. Molecular diagnostics clinical laboratory science course design: Making it real. Clin Lab Sci 2009;22(1):9-15.

54. Josko D. Molecular bacteriology in the clinical laboratory. Clin Lab Sci 2010;23(4):237-41.

55. Leibach E. K., Russell B. L. A typology of evidence based practice research heuristics for clinical laboratory science curricula. Clin Lab Sci 2010;23(3)Suppl:46-51.

56 Leibach, E. K. Redefining patient safety in the clinical laboratory. Clin Lab Sci 2013;26(4)Suppl:198-9.

57. Leibach EK. The doctorate in clinical laboratory science: A view of the strategy for continuity, growth, and realization of potential. Clin Lab Sci 2007;20(3):132-5.

58. Leibach EK. The future of the profession. Clin Lab Sci 2011;24(4):2-3.

59. ASCLS DCLS Oversight Committee. The DCLS Tool Kit. [cited 2014 Sept 27[ Available from http://www.ascls.org/ educator-s-information/dcls-tool-kit-a-resource-for-educators

60. Morris S. Unification of the NCA and the ASCP Board of Registry. Clin Lab Sci 2010;23(1):2-4.

61. ASCLS. Personnel Licensure. 2014 [cited 2014 Sep 27] Available from http://www.ascls.org/educator-s-information/ career-recruitment-tool-kit/161-personnel-licensure

62. Esani M. Moving from face-to-face to online teaching. Clin Lab Sci 2010;23(3):187-90.

63. Hammerling JA. Best practices in undergraduate clinical laboratory science online education and effective use of educational technology tools. Lab Med 2012;43(6):313-9.

64. McCown LJ. Blended courses: The best of online and traditional formats. Clin Lab Sci 2010;23(4):205-11.

65. Castillo D. The effectiveness of digital microscopy as a teaching tool in medical laboratory science curriculum. Clin Lab Sci 2012;25(4):4-11.

66. Conway-Klaassen JM, Wiesner SM, Desens C, Trcka P, Swinehart C. Using online instruction and virtual laboratories to teach hemostasis in a medical laboratory science program. Clin Lab Sci 2012;25(4):224-9.

67. Solberg BL. Student perceptions of digital versus traditional slide use in undergraduate education. Clin Lab Sci 2012;25(4)19-25.

68. Beadling W, Vossler J. Problem-based learning in the clinical laboratory science curriculum. Lab Med 2001;32(8):422-30.

69. Behan KJ. Teaching research design and practice one bite at a time in the MT/CLS curriculum. Lab Med 2007;38(10):58296.

70. Mundt L, Vanik J. Clinical laboratory sciences curriculum 
redevelopment: An application of change theories. Clin Lab Sci 2007;20(2):72-9.

71. Freeman VS. Focus: Online education and technology introduction. Clin Lab Sci 2010:23(3) Suppl:3-51-2.
72. Best ML. Medical technologists: Changing roles in a changing environment. Lab Med 1993;24(7):399-401.

73. Ikeda K. Twelve years of registry and its contribution to medical technology. Am J Med Tech 1940;6:222-34.

\section{ASCLS MEMBER RENEWAL THANK YOU}
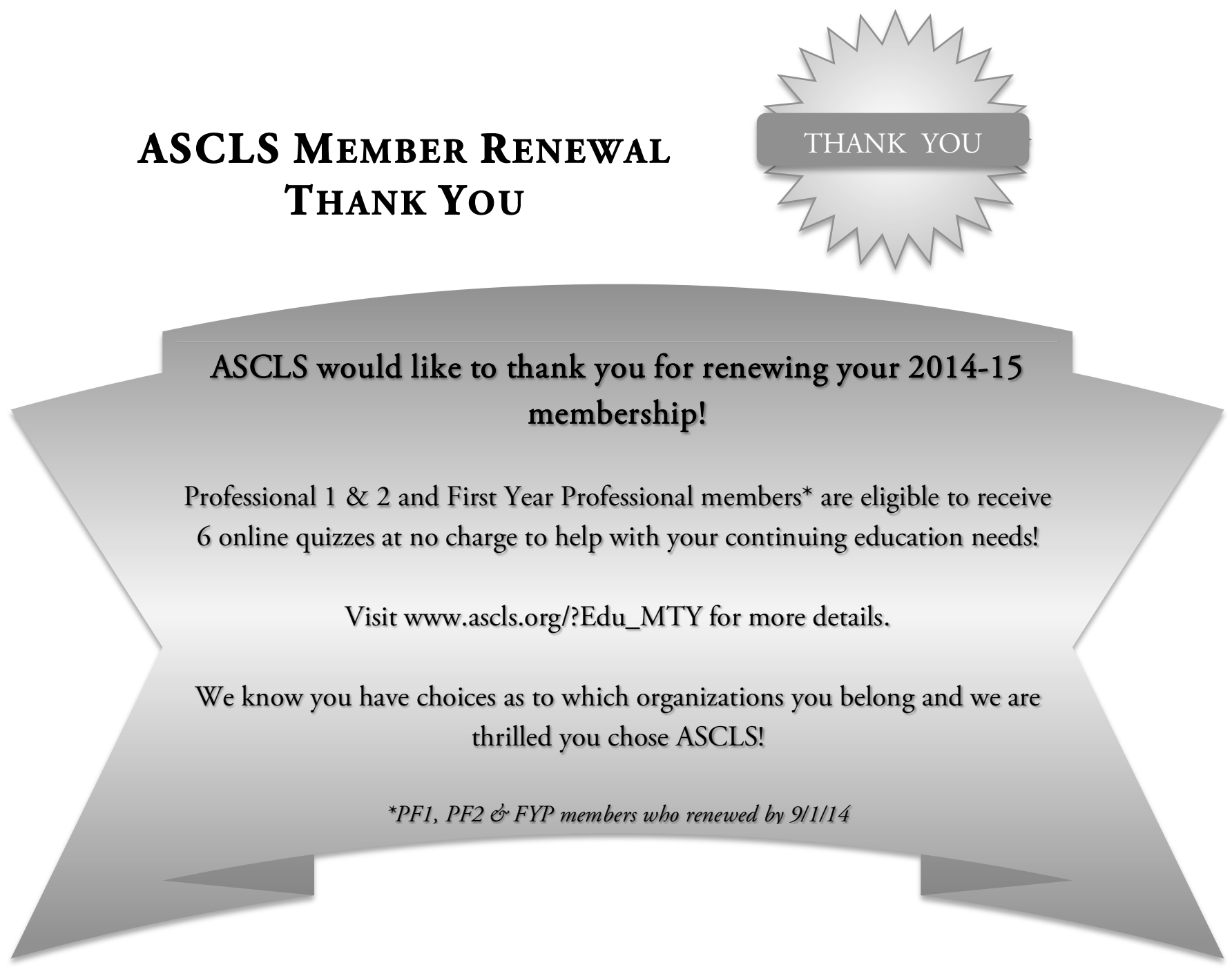

The peer-reviewed Education Section seeks to publish reports of original research related to the clinical laboratory or one or more subspecialties, as well as information on important clinical laboratory-related topics such as technological, clinical, and experimental advances and innovations. Literature reviews are also included. Direct all inquiries to Elizabeth Kenimer Leibach, EdD, MS, $M L S(A S C P)^{C M} S B B^{C M}$, Professor Emeritus, Departments of Biomedical and Radiological Technologies and Pathology, Georgia Regents University, EC 2437, Augusta, GA 30912, eleibach@comcast.net. Clinical Laboratory Science encourages readers to respond with thoughts, questions, or comments regarding these articles. Email responses to editor@westminsterpublishers.com. In the subject line, please type the journal issue and lead author such as "CLIN LAB SCI 27(4) RE BUTINA". Selected responses may appear in the Dialogue and Discussion section in a future issue. Responses may be edited for length and clarity. We look forward to hearing from you. 